1974

\title{
Hydrates in supersaturated binary sulfuric acid-water vapor
}

\author{
Richard H. Heist \\ Fairfield University, rheist@fairfield.edu \\ H. Reiss
}

Follow this and additional works at: https://digitalcommons.fairfield.edu/engineering-facultypubs (C) 1974 American Institute of Physics.

The final publisher PDF has been archived here with permission from the copyright holder. https://aip.scitation.org/doi/abs/10.1063/1.1681932

\section{Peer Reviewed}

\section{Repository Citation}

Heist, Richard H. and Reiss, H., "Hydrates in supersaturated binary sulfuric acid-water vapor" (1974). Engineering Faculty Publications. 164.

https://digitalcommons.fairfield.edu/engineering-facultypubs/164

\section{Published Citation}

Heist, R. H., \& Reiss, H. (1974). Hydrates in supersaturated binary sulfuric acid-water vapor. The Journal of Chemical Physics, 61(2), 573-581. doi:10.1063/1.1681932.

This item has been accepted for inclusion in DigitalCommons@Fairfield by an authorized administrator of DigitalCommons@Fairfield. It is brought to you by DigitalCommons@Fairfield with permission from the rightsholder(s) and is protected by copyright and/or related rights. You are free to use this item in any way that is permitted by the copyright and related rights legislation that applies to your use. For other uses, you need to obtain permission from the rights-holder(s) directly, unless additional rights are indicated by a Creative Commons license in the record and/or on the work itself. For more information, please contact digitalcommons@fairfield.edu. 


\title{
Hydrates in supersaturated binary sulfuric acid-water vapor
}

\author{
R. $\mathrm{H}$. Heist and H. Reiss
}

Department of Chemistry, University of California, Los Angeles, California 90024

(Received 12 March 1974)

\begin{abstract}
Portions of the free energy surface giving the reversible work $W$ required to form a droplet containing $n_{1}$ molecules of $\mathrm{H}_{2} \mathrm{O}$ and $n_{2}$ molecules of $\mathrm{H}_{2} \mathrm{SO}_{4}$ from an initially homogeneous vapor have been calculated for a variety of relative humidities and $\mathrm{H}_{2} \mathrm{SO}_{4}$ vapor concentrations. These surfaces are displayed as three dimensional perspective plots. The surfaces predict the existence of stable $\mathrm{H}_{2} \mathrm{SO}_{4}$ hydrates in the vapor phase, and the number of hydrates, $N_{h}$, with $h$ molecules of $\mathrm{H}_{2} \mathrm{O}$ per hydrate has been calculated for three different values of the relative humidity. The results of these calculations indicate that virtually all the $\mathrm{H}_{2} \mathrm{SO}_{4}$ present, especially for relative humidities greater than $100 \%$, exists in hydrate form. As the relative humidity is increased (i.e., greater than $200 \%$ ), the distribution of hydrate sized agrees well with that found by Giauque et al. for solid $\mathrm{H}_{2} \mathrm{O}-\mathrm{H}_{2} \mathrm{SO}_{4}$ mixtures. Hydrate formation can exert an appreciable effect on the process of vapor phase nucleation in $\mathrm{H}_{2} \mathrm{O}-\mathrm{H}_{2} \mathrm{SO}_{4}$ mixtures, and must be considered in any theory of nucleation rate.
\end{abstract}

\section{INTRODUCTION}

Recently there have been a number of papers $\mathrm{s}^{1-5}$ dealing with the role of sulfuric acid in atmospheric aerosol formation. Two papers $\mathrm{s}^{6,7}$ have also addressed the rather careful application of binary nucleation theory to sulfuric acid-water vapor mixtures. Both papers reach the similar conclusion that incredibly small amounts of $\mathrm{SO}_{3}$ or $\mathrm{H}_{2} \mathrm{SO}_{4}$ are capable of nucleating water droplets. For example, even in unsaturated water vapor, e.g. , at a relative humidity of $50 \%$, nucleation is predicted at sulfuric acid partial pressures as low as $10^{-9}$ torr. Of course, although undersaturated with respect to pure water, the mixture under these conditions is supersaturated with respect to sulfuric acid solution. The very effective nucleating ability of sulfuric acid has been confirmed in a qualitative manner by several investiga tors, ${ }^{1-5}$ and the present authors are conducting experiments on the photo-oxidation of sulfur dioxide (to be reported in a later paper) in which this behavior is reaffirmed in a rather quantitative manner.

As a result of our most recent considerations in this respect, we have concluded that the theoretical work of Doyle $^{6}$ and Mirabel and $\mathrm{Katz}^{7}$ on binary nucleation in $\mathrm{H}_{2} \mathrm{SO}_{4}$-water mixtures, using a method described by Reiss, ${ }^{8}$ omits an important factor, viz., hydrate formation. In spite of this, of course, the works of Doyle and Mirabel and Katz, internally consistent, do provide valuable insight into the phenomenon; and, as we shall see, the free energy surfaces with which they work are useful to a theory which includes the effects of hydration.

The fact that hydrates are important in the sulfuric acid-water system is by no means a new idea. Giauque and his collaborators ${ }^{9}$ have published a phase diagram indicating the existence of six distinct solid hydrate phases. These are $\mathrm{H}_{2} \mathrm{SO}_{4} \cdot \mathrm{H}_{2} \mathrm{O}, \mathrm{H}_{2} \mathrm{SO}_{4} \cdot 2 \mathrm{H}_{2} \mathrm{O}, \mathrm{H}_{2} \mathrm{SO}_{4}$ - $3 \mathrm{H}_{2} \mathrm{O}, \mathrm{H}_{2} \mathrm{SO}_{4} \cdot 4 \mathrm{H}_{2} \mathrm{O}, \mathrm{H}_{2} \mathrm{SO}_{4} \cdot 6.5 \mathrm{H}_{2} \mathrm{O}$, and $\mathrm{H}_{2} \mathrm{SO}_{4} \cdot 8 \mathrm{H}_{2} \mathrm{O}$, the last being speculative. Given the obvious strong binding energy between $\mathrm{H}_{2} \mathrm{SO}_{4}$ and the water molecule, one would expect hydrate formation in the vapor phase, especially when water vapor is present in great excess over sulfuric acid. The situation would be even more extreme at supersaturations corresponding to relative humidities of several hundred percent. In these cases, hydrates in which several water molecules are bound to a single $\mathrm{H}_{2} \mathrm{SO}_{4}$ molecule might be expected. As we shall see below, theoretical estimates based on the liquid drop model of nucleation theory strongly support this conclusion. The thermodynamic data of Giauque $e t$ al., 9 collected originally for the purpose of identifying hydrates in the solid phase, prove capable, with the help of the liquid drop model and additional data ${ }^{10}$ on the surface tensions of sulfuric acid solutions, of also characterizing hydrates in the vapor phase.

As we have indicated earlier, hydrate formation requires adjustments to be made in the theory of nucleation, and we present the adjusted theory in a following paper. Here we concern ourselves with the equilibrium aspects of hydrate formation, and with certain features of the free energy surface associated with the nucleation process.

\section{FREE ENERGY OF FORMATION OF HYDRATES AND HYDRATE EQUILIBRIA}

If we treat the hydrate as a liquid drop, as in conventional nucleation theory, ${ }^{11}$ the free energy expended in producing a single hydrate molecule (or cluster if this should prove a more appropriate way to describe the entity) may be assumed to equal the free energy or reversible work required in the production of a drop eontaining one $\mathrm{H}_{2} \mathrm{SO}_{4}$ molecule and $h$ water molecules from the initially homogeneous vapor phase. This quantity, which we denote by $W_{h}^{\prime}$, is then given by

$$
W_{h}^{\prime}=\mu_{2}-\phi_{2}+h\left(\mu_{1}-\phi_{1}\right)+\sigma(1, h) A(1, h) .
$$

In this equation, $\phi_{2}$ is the chemical potential of a sulfuric acid molecule in the vapor phase, presumed homogeneous, while $\phi_{1}$ is the chemical potential of a water molecule. Similarly, $\mu_{2}$ is the chemical potential of a sulfuric acid molecule in bulk liquid solution having the composition of the hydrate, while $\mu_{1}$ is the chemical potential of a water molecule in the same solution. The quantity $\sigma(1, h)$ is the surface tension of a solution having the composition of a hydrate with one acid and $h$ water molecules, while $A(1, h)$ is the surface area of a spherical drop consisting of one acid and $h$ water molecules. 
In the conventional theory of nucleation, one considers the various clusters which form in a supersaturated vapor as though they were individual molecular species, the entire mixture forming an ideal system. The chemical potential of a hydrate cluster may then be represented as

$$
\phi_{h}=\phi_{h}^{0}(T, p)+k T \ln \left(N_{h} / N_{t}\right),
$$

where $\phi_{h}^{0}$ is the chemical potential in the standard state, depending only on temperature $T$ and pressure $p$; while $N_{h}$ is the number of hydrate clusters in the mixture, $N_{t}$ is the total number of molecular species of all types, including water molecules, and $k$ is the Boltzmann constant. In conventional nucleation theory, $\phi_{h}^{0}$ is usually taken to be the free energy of the equivalent drop, or simply (what is the same thing within the framework of the model) the free energy per hydrate cluster in a gas of pure hydrate. Thus, we write

$$
\phi_{h}^{0}(T, p)=\mu_{2}+h \mu_{1}+\sigma(1, h) A(1, h) .
$$

The condition of chemical equilibrium for the reaction corresponding to the formation of hydrate is

$$
\phi_{2}+h \phi_{1}=\phi_{h} .
$$

Substitution of Eq. (3) into (2) and the result into (4) leads to the relation

$$
N_{h}=N_{t} e^{-W h / k T} \text {. }
$$

Since we shall be interested in situations where the number of water molecules far exceeds the number of acid molecules (and certainly the number of clusters), we may replace $N_{t}$ by $N$, the number of water molecules alone. Then Eq. (5) becomes

$$
N_{h}=N e^{-W / k T} \text {. }
$$

Now $W_{h}^{\prime}$ itself depends on $N_{h}$, so Eq. (6) still requires some rearrangement in order to isolate $N_{h}$. We accomplish this as follows.

In Refs. 6 and 7 the nucleation process is discussed for conditions such that the partial pressures in the supersaturated phase of both acid and water are fixed. If sulfuric acid molecules are distributed throughout several species of hydrate, it is impractical, in the laboratory, to maintain the partial pressure of $\mathrm{H}_{2} \mathrm{SO}_{4}$ fixed. In many real situtations, however, it is possible to fix the total number of acid molecules, no matter how they may be distributed in hydrates. Alternatively, in fixed volume the total concentration of acid molecules may be fixed, again neglecting how they may be distributed. In fact this is the usual situation. If we denote the total number of acid molecules by $N_{a}$, then the partial pressure due to acid, if none of the acid molecules were hydrated, would be

$$
P_{2}=N_{a} k T / V,
$$

where $V$ is the volume of this vapor. The actual partial pressure of sulfuric acid is given by

$$
p_{2}=\left(N_{a}-\sum_{h} N_{n}\right) k^{\prime} T / V,
$$

where the sum goes over all hydrate species.

Since the vapor mixture is considered to be an ideal gas, we may write

$$
\begin{aligned}
& \phi_{1}=B_{1}(T)+k T \ln p_{1}, \\
& \phi_{2}=B_{2}(T)+k T \ln p_{2},
\end{aligned}
$$

where $B_{1}$ and $B_{2}$ depend only on the temperature. If $p_{1}^{0}$ and $p_{2}^{0}$ are the equilibrium partial vapor pressures of water and acid above a solution having the composition of the hydrate, we can express $\mu_{1}$ and $\mu_{2}$, except for a negligible term of the order of $v\left(p_{1}-p_{1}^{0}\right)$, where $v$ is a quantity of the order of the volume per molecule in the liquid, in the forms

$$
\begin{aligned}
& \mu_{1}=B_{1}(T)+k T \ln p_{1}^{0}, \\
& \mu_{2}=B_{2}(T)+k T \ln p_{2}^{0} .
\end{aligned}
$$

Substitution of Eqs. (9)-(12) into (1) yields

$$
W_{h}^{\prime}=k T \ln \left(p_{2}^{0} / p_{2}\right)+h k T \ln \left(p_{1}^{0} / p_{1}\right)+\sigma(1, h) A(1, h) .
$$

If there were no hydrate formation, then $p_{2}$ would be replaced by $P_{2}$, and the reversible work of hydrate formation would be given an expression of the same form as Eq. (13) with $p_{2}$ replaced by $P_{2}$. We denote the reversible work in this instance by

$$
W_{h}=k T \ln \left(p_{2}^{0} / P_{2}\right)+h k T \ln \left(p_{1}^{0} / p_{1}\right)+\sigma(1, h) A(1, h)
$$

in which we have dropped the prime. This is in fact the free energy function to which Doyle $e^{6}$ and Mirabel and $\mathrm{Katz}^{7}$ addressed themselves. Comparison of Eqs. (13) and (14) leads to the relation

$$
W_{h}^{\prime}=W_{h}+k T \ln \left(P_{2} / p_{2}\right),
$$

so that detailed calculations concerning $W_{h}$ can be utilized in the computation of $W_{h}^{\prime}$.

It is convenient to define $\theta$ as follows:

$$
\theta=\sum_{h} N_{h} \text {. }
$$

Substitution of Eq. (16) into (8), and of Eqs. (7) and (8) into (15), yields

$$
W_{h}^{\prime}=W_{h}-k T \ln \left[1-\left(\theta / N_{h}\right)\right],
$$

and substitution of Eq. (17) into (6) gives

$$
N_{h}=N\left[1-\left(\theta / N_{a}\right)\right] e^{-W_{h} / k T} .
$$

Summation of Eq. (18) over all values of $h$ gives

$$
\theta=N\left[1-\left(\theta / N_{a}\right)\right] Q,
$$

in which $Q$ is defined as

$$
Q=\sum_{h} e^{-W_{h} / k T} \text {. }
$$

Solving Eq. (19) for $\theta$ gives

$$
\theta=\frac{N_{a}}{1+N_{a} / N Q} .
$$

Substitution of Eq. (21) into (18) yields

$$
N_{h}=\frac{N_{a}}{Q+N_{a} / N} e^{-W_{h} / k T} .
$$

If $N_{a} / N \ll Q$, which is likely since we shall be interested in vapor mixtures containing typically less than one part per million of $\mathrm{H}_{2} \mathrm{SO}_{4}$, this becomes 


$$
N_{h}=N_{a} e^{-W_{h} / k T} / Q \text {. }
$$

Equation (22) or (23) is the formula which expresses the number of hydrate clusters in terms of the total number of sulfuric acid molecules available, and $W_{h}$, the reversible work around which the theory in Refs. 6 and 7 is developed. Notice that if one of the hydrates, say $h^{\prime}$, dominates the sum in $Q$, then Eq. (23) requires

$$
N_{h}^{\prime}=N_{a},
$$

i. e., all of the sulfuric acid molecules are bound in that hydrate species.

\section{SOME REMARKS CONCERNING $w_{h}$}

Equation (23) indicates that hydrate concentrations can be computed using the free energy function $W_{h}$, conventional in the past. The usual point of view in regard to this function has been that the independently variable components of the binary system were $\mathrm{H}_{2} \mathrm{SO}_{4}$ and water. Of course, this is a perfectly acceptable point of view, provided that the relevant thermodynamics is performed consistently. In fact, since the total sulfuric acid content is easily measurable while the individual hydrate concentrations are not, it would be impractical to choose a hydrate as one of the independent components. The activities of these components have usually been referred to the pure substances as standard. ${ }^{9}$ Thus, the activities in the liquid of water and acid, respectively, are defined as

$$
\begin{aligned}
& a_{1}^{l}=p_{1}^{0} / p_{1}^{00}, \\
& a_{2}^{l}=P_{2}^{0} / p_{2}^{00} .
\end{aligned}
$$

In these equations, $p_{1}^{00}$ and $p_{2}^{00}$ represent the vapor pressures of the pure components; while $p_{1}^{0}$ and $p_{2}^{0}$, as before, are the partial pressures over the solution of appropriate composition. The quantity $p_{2}^{00}$ is actually the partial pressure of $\mathrm{H}_{2} \mathrm{SO}_{4}$ in the vapor above pure liquid $\mathrm{H}_{2} \mathrm{SO}_{4}$; $\mathrm{SO}_{3}$ and $\mathrm{H}_{2} \mathrm{O}$ are also present as a result of dissociative equilibrium. The use of $a_{2}$, therefore, requires knowledge of the partial pressure of $\mathrm{H}_{2} \mathrm{SO}_{4}$ over pure sulfuric acid, a quantity whose magnitude is known only approximately. More work on the vapor pressure of pure sulfuric acid is desirable.

Both $a_{1}$ and $a_{2}$ are introduced into $W_{h}^{\prime}$ and $W_{h}$ through the quantities $p_{1}^{0} / p$ and $p_{2}^{0} / p_{2}$ which appear in Eq. (13). Thus, we have

$$
p_{1}^{0} / p_{1}=a_{1}^{l} p_{1}^{00} / p_{1}=a_{1}^{l} / S_{1}^{0}=a_{1}^{l} / a_{1}
$$

and

$$
p_{2}^{0} / p_{2}=a_{2}^{l} p_{2}^{00} / p_{2}=a_{2}^{l} / S_{2}^{0}=a_{2}^{l} / a_{2} ，
$$

in which $S_{1}^{0}=a_{1}=p_{1} / p_{1}^{00}$ and $S_{2}^{0}=a_{2}=p_{2} / p_{2}^{00}$ are activities or saturations of water and $\mathrm{H}_{2} \mathrm{SO}_{4}$ referred to the pure liquids, respectively.

In Refs. 6 and 7, free energy surfaces are considered for constant values of $S_{2}^{0}$ and the corresponding quantity $S_{1}^{0}$ for water; and the value of $p_{2}^{00}$ is estimated. Reference 6 places $p_{2}^{00}$ at $10^{-6}$ torr, while Ref. 7 argues that it is closer to $10^{-4}$ torr.

In connection with Eq. (23), it should be noted that the conventional procedure of nucleation theory is utilized in which a constraint must be imposed which disallows the existence of clusters larger than the "nuclear" size corresponding to any maximum in $W_{h}$. Otherwise drops larger than nuclei would form and the sums involved in both $\theta$ and $Q$ would diverge. In effect the application of this formal constraint converts a metastable equilibrium into one that is stable. It should also be noted that in discussing hydrates we have specifically limited our attention to clusters containing only one sulfuric acid molecule. Clusters involving more than one acid molecule can exist and, as we shall show in a following paper, are of central importance to the nucleation process itself. However, from the equilibrium point of view, they are usually present in such small numbers that they need not be considered in forming the sums corresponding to $\theta$ and $Q$. There is also a question, somewhat semantic in nature, as to whether it is appropriate to refer to these multiacid-molecule clusters as hydrates in the strict sense. Sulfuric acid hydrates in the vapor phase may be well defined molecular species, although at high levels of supersaturation, with respect to water, water molecules may add to a well defined species to produce a more loosely defined entity which nevertheless is present in reasonable concentration.

We have computed the free energy surface corresponding to $W_{h}$ under various conditions of supersaturation and temperature using, as in the case of Refs. 6 and 7, data obtained from Refs. 9 and 10. Whereas Refs. 6 and 7 are confined to establishing the existence and location of saddle points on the surface, and the use of the properties of such saddle points in the theory of Ref. 8, we have attempted to compute appreciable portions of the surface. As a result, we can detect minima (valleys), maxima (ridges), and saddle points. The minima correspond to the formation of hydrates and, as is evident from what follows below, hydrates do indeed form. The presence of hydrates requires some modification of theory set forth in Refs. 6 and 8 . We shall return to this subject in another paper, but for the moment move on to a quantitative examination of $W_{h}$ and $N_{h}$.

\section{THE FREE ENERGY SURFACE}

The free energy, or reversible work, required to form a drop with $n_{1} \mathrm{H}_{2} \mathrm{O}$ molecules and $n_{2} \mathrm{H}_{2} \mathrm{SO}_{4}$ molecules can be written as

$$
W=n_{1}\left(\mu_{1}-\phi_{1}\right)+n_{2}\left(\mu_{2}-\phi_{2}\right)+4 \pi r^{2} \sigma,
$$

where we have assumed the conventional liquid drop model. In Eq. (29), $\mu_{1}$ and $\mu_{2}$ represent the chemical potentials per molecule for $\mathrm{H}_{2} \mathrm{O}$ and $\mathrm{H}_{2} \mathrm{SO}_{4}$ taken in the bulk liquid phase, respectively, while the $\phi$ 's represent the chemical potentials per molecule in the vapor phase, $r$ is the radius of the drop, and $\sigma$ is the surface tension, also taken for bulk solution. Equation (29) is written choosing $\mathrm{H}_{2} \mathrm{SO}_{4}$ and $\mathrm{H}_{2} \mathrm{O}$ as independently variable components; the standard states are pure $\mathrm{H}_{2} \mathrm{SO}_{4}$ and pure $\mathrm{H}_{2} \mathrm{O}$. These standard states are consistent with the thermodynamic data available and used to compute the surface. 
Partial molar free energies used in computing our free energy surfaces were obtained from the bulk solution data of Giauque et al. ${ }^{9}$ As indicated, these authors used pure $\mathrm{H}_{2} \mathrm{O}$ and pure $\mathrm{H}_{2} \mathrm{SO}_{4}$ as standard states. Partial molar free energy data, ranging from $100 \%$ to $8.93 \%$ by weight $\mathrm{H}_{2} \mathrm{SO}_{4}$, were fit to cubic polynomials with errors, due to curve fitting, of only a few hundredths of a percent over the entire range, thus permitting accurate interpolation. The only remaining significant source of error was in the experimental measurements and was estimated to be about $1 \%$ or less. ${ }^{9,12}$

Partial molar volumes used to compute the drop radius were derived from bulk solution density measurements tabulated in the Chemical Engineer's Handbook. ${ }^{13}$ Specific volumes of the solution were fit to an eighth order polynomial so that the difference between a computed and experimental point was always less than $0.08 \%$. Partial molar volumes were then determined by calculating the specific volume of solution as a function of percent $\mathrm{H}_{2} \mathrm{SO}_{4}$, computing the tangent to this curve at a given percent composition and analytically determining the points of interception of this tangent with the ordinates. ${ }^{14}$

Measurements of the surface tension of $\mathrm{H}_{2} \mathrm{SO}_{4}-\mathrm{H}_{2} \mathrm{O}$ solutions have been published by Sabinina and Terpagow. ${ }^{10}$ These data, in the range $0-100 \%$ by weight $\mathrm{H}_{2} \mathrm{SO}_{4}$, were fit to several fourth order polynomials so that the error due to curve fitting was generally less than $0.1 \%$ over the entire range. A more complete set of surface tension measurements appears in a paper by Morgan and Davis ${ }^{15}$; their values are generally lower and differ by as much as $5 \%$ from those of Sabinina and Terpugow. Variations of this magnitude in the surface tension effect significant changes in the free energy surface. We chose to use Sabinina and Terpugow's data on the somewhat weak basis that it is more recent. Such discrepancies in experimental data must be kept in mind, however, when assessing the features of the calculated free energy surface. A more detailed discussion is given in Sec. V of this paper.

Portions of the free energy surface for $\mathrm{H}_{2} \mathrm{SO}_{4}-\mathrm{H}_{2} \mathrm{O}$ droplet formation have been computed for various conditions representative of those generally employed in our laboratory or found in the natural environment. Each surface corresponds to a particular relative humidity $R H$ and a particular acid vapor activity $a_{2}$. Both $R H$ and $a_{2}$ are defined in Eqs. (25) and (26), respectively. If $a_{2}$ is to be related to acid vapor concentration, the equilibrium vapor pressure of pure $\mathrm{H}_{2} \mathrm{SO}_{4}$ must be known. As mentioned earlier, this vapor pressure is quite small and its exact value somewhat uncertain. The most reasonable value seems to be that given by Gimitro and Vermeulen ${ }^{16}$ as $3.6 \times 10^{-4} \mathrm{~mm}$ at $25^{\circ} \mathrm{C}$, and we shall use this value in our calculations. In computing the free energy surfaces for this paper, we take $a_{2}$ to be either $10^{0}, 10^{-3}$, or $10^{-5}$. With the accepted value for the vapor pressure of pure $\mathrm{H}_{2} \mathrm{SO}_{4}$, these correspond to order-ofmagnitude concentrations of parts per million ( $\mathrm{ppm}$ ), parts per billion (ppb), and 10 parts per trillion (ppt), respectively. For each of the computed surfaces the $R H$. is taken to be either $50 \%, 200 \%$, or $300 \%$. A $R H$ of $200 \%$ corresponds to a supersaturation of 2 , while $50 \%$ is below saturation as in the atmosphere. Each of the surfaces illustrated in this paper are computer generated, three dimensional perspective plots. All plots are drawn in such a fashion that the viewer appears to be looking down on the surface at a polar angle $\psi$ of $45^{\circ}$ from the vertical axis; and, with the exception of Fig. 5 , an azimuthal angle $\xi$ about this axis of $315^{\circ}$. The perspective corresponds to the observer being at a distance $d$ four cube diagonals away from the origin. These values of $\psi, \xi$, and $d$ give the viewer the impression he is sitting behind and above the origin looking over the surface out into "left field." Viewing the surfaces and resolving their salient features sometimes require enough concentration to avoid optical illusion.

Because a number of interesting features are demonstrated rather clearly, we have presented one surface viewed from two different angles to help clarify its general shape. Figure 5 shows the identical surface as in Fig. 4 except that $\xi$ is $120^{\circ}$. With $\psi=45^{\circ}, \xi=120^{\circ}$, the viewer has the impression he is observing the surface from high in "left field" looking back over the origin. This particular view clearly shows a valley running along the surface with walls rising on either side. We have chosen to represent most of the plots at $\psi=45^{\circ}$, $\xi=315^{\circ}$, and $d=4$ because in our opinion this vantage point brings out interesting features more clearly.

Figures 1 and 2 correspond to $R H=50 \%$ and $a_{2}=10^{\circ}$ and $10^{-3}$, respectively; Figs. 3-6 show surfaces, each corresponding to $R H=200 \%$ and $a_{2}=10^{\circ}$ for Fig. $3,10^{-3}$ for Figs. 4 and 5 , and $10^{-5}$ for Fig. 6. Again, Figs. 4 and 5 are the same surface viewed from two different positions. Figures 7-9 depict surfaces for which $R H$ $=300 \%$ and $a_{2}=10^{0}, 10^{-3}$, and $10^{-5}$, respectively. The surfaces all have been drawn inside rectangular parallelepipeds to aid in the viewer's perspection. All parallelepipeds are the same physical size and each plot has been scaled to fit inside. The maximum and minimum values of $W$ for a particular set of conditions correspond to the vertical dimensions of the parallelepiped and are marked on each plot. The horizontal axes, $n_{1}$ and $n_{2}$, correspond in each case, except Fig. 2, to 40 $\mathrm{H}_{2} \mathrm{O}$ molecules along the $n_{1}$ axis and $10 \mathrm{H}_{2} \mathrm{SO}_{4}$ molecules along the $n_{2}$ axis. In Fig. 2, the $n_{1}$ and $n_{2}$ axes are scaled for $63 \mathrm{H}_{2} \mathrm{O}$ and $18 \mathrm{H}_{2} \mathrm{SO}_{4}$ molecules, respectively. In all cases, $n_{1}$ and $n_{2}$ and $W$ equal zero at the origin, and increase along their respective axes with maximum values occurring at the corners of the parallelepiped. The scales for $n_{1}, n_{2}$, and $W$ are all linear.

Among the interesting features depicted in these plots are the values of $W$ along each of the two axes $n_{1}$ and $n_{2}$. The plot along the $n_{1}$ axis corresponds to $n_{2}=0$ and thus to ordinary homogeneous nucleation of $\mathrm{H}_{2} \mathrm{O}$. This plot increases continuously in Figs. 1 and 2, as it should for a $R H$ of $50 \%$, i.e., no nucleation occurs in undersaturated vapors. In Figs. 3-9, $W$ begins to level off and would eventually go through a maximum at the value of $n_{1}$ corresponding to the critical nucleus. When the plots are viewed along the $n_{1}$ axis, a given value of $W$ for a particular $R H$ and $n_{1}$ seems to change from one figure to the next; e.g., compare Figs. 4 and 6 with 


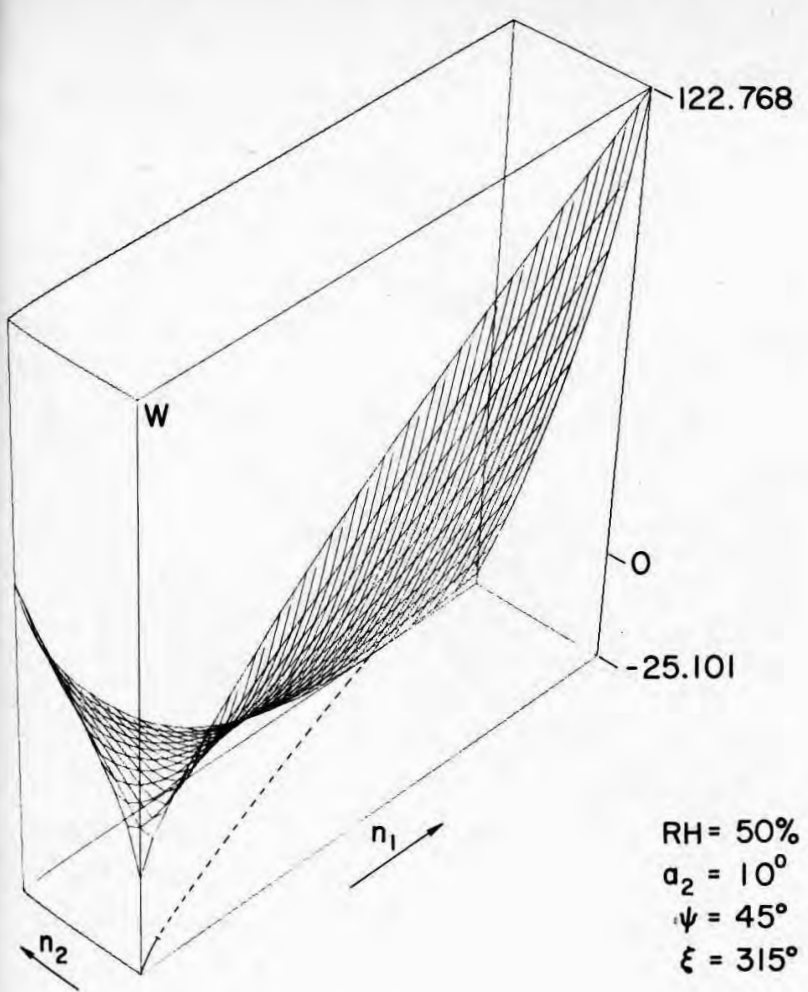

FIG. 1. The free energy surface for $\mathrm{H}_{2} \mathrm{O}-\mathrm{H}_{2} \mathrm{SO}_{4}$ droplet formation of $25^{\circ} \mathrm{C}$ with $R H=50 \%$ and $a_{2}=10^{\circ}$. $n_{1}$, the number of $\mathrm{H}_{2} \mathrm{O}$ molecules, and $n_{2}$, the number of $\mathrm{H}_{2} \mathrm{SO}_{4}$ molecules, range from 0 to 40 and 0 to 10 , respectively, and increase in the directions indicated by the arrows. The maximum and minimum values of the free energy $W$ are given on the plot. All the scales shown are linear. The projection of the path of minimum free energy through the saddle point is shown on the parallelepiped base. The ending of the solid line represents the saddle point. The viewing angles are $\psi=45^{\circ}$ down from the $W$ axis and $\xi=315^{\circ}$ about the $W$ axis. See the text for details of the viewer perspection.

$n_{1}=40$. However, $W$ is the same; only the maximum and minimum values for the respective surfaces have changed because $a_{2}$ has changed, and the plot has been scaled accordingly (see above). Along the $n_{2}$ axis, the variation of $W$ with $n_{2}$ corresponds to the homogeneous nucleation of $\mathrm{H}_{2} \mathrm{SO}_{4}$. With an equilibrium vapor pressure of $3.6 \times 10^{-4} \mathrm{~mm}$, acid vapor activities of $10^{-3}$ and $10^{-5} \mathrm{cor}-$ respond to states undersaturated with respect to pure $\mathrm{H}_{2} \mathrm{SO}_{4}$. The very large and sharp increase of $W$ with $n_{2}$ in Figs. 2, 4, 5, 6, 8, and 9 clearly indicates this undersaturation. When $a_{2}=10^{\circ}$, however, the $\mathrm{H}_{2} \mathrm{SO}_{4}$ vapor is saturated, i.e., $S=1$; and, as shown in Figs. 1,3 , and 7 , the plot of $W$ versus $n_{2}$ is beginning to reflect this saturation.

Perhaps the most dominant feature of the surfaces is the saddle point first predicted by Reiss ${ }^{8}$ and located by Doyle ${ }^{6}$ and Mirabel and Katz. ${ }^{7}$ According to Ref. 8, it is along the valley and over this saddle that a $\mathrm{H}_{2} \mathrm{O}-\mathrm{H}_{2} \mathrm{SO}_{4}$ droplet grows as it adds single $\mathrm{H}_{2} \mathrm{O}$ and single $\mathrm{H}_{2} \mathrm{SO}_{4}$ molecules. The saddle point becomes more pronounced as the acid vapor activity is increased and/or as relative humidity is increased. For smaller values of $R H$ and $a_{2}$, the exact location of the saddle point is unclear

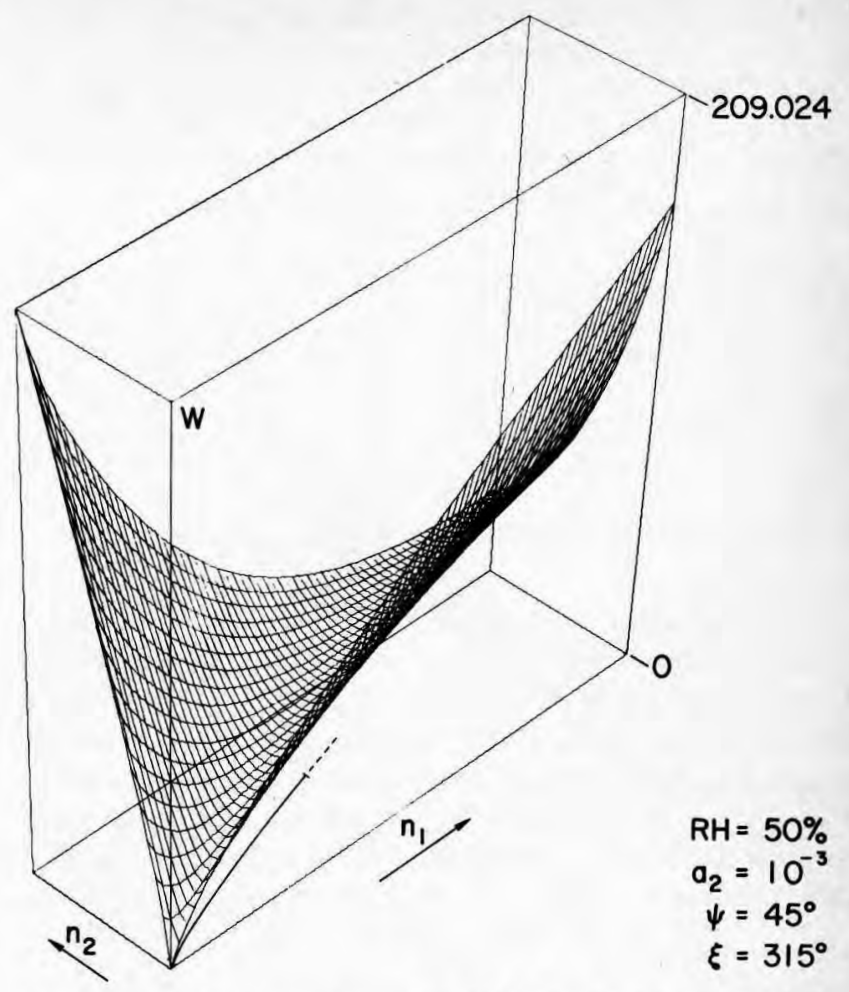

FIG. 2. The free energy surface for $\mathrm{H}_{2} \mathrm{O}-\mathrm{H}_{2} \mathrm{SO}_{4}$ droplet formation at $25^{\circ} \mathrm{C}$ with $R H=50 \%$ and $a_{2}=10^{-3}$. $n_{1}$, the number of $\mathrm{H}_{2} \mathrm{O}$ molecules, and $n_{2}$, the number of $\mathrm{H}_{2} \mathrm{SO}_{4}$ molecules, range from 0 to 63 and 0 to 18 , respectively, and increase in the directions indicated by the arrows. The remaining conditions are the same as in Fig. 1.

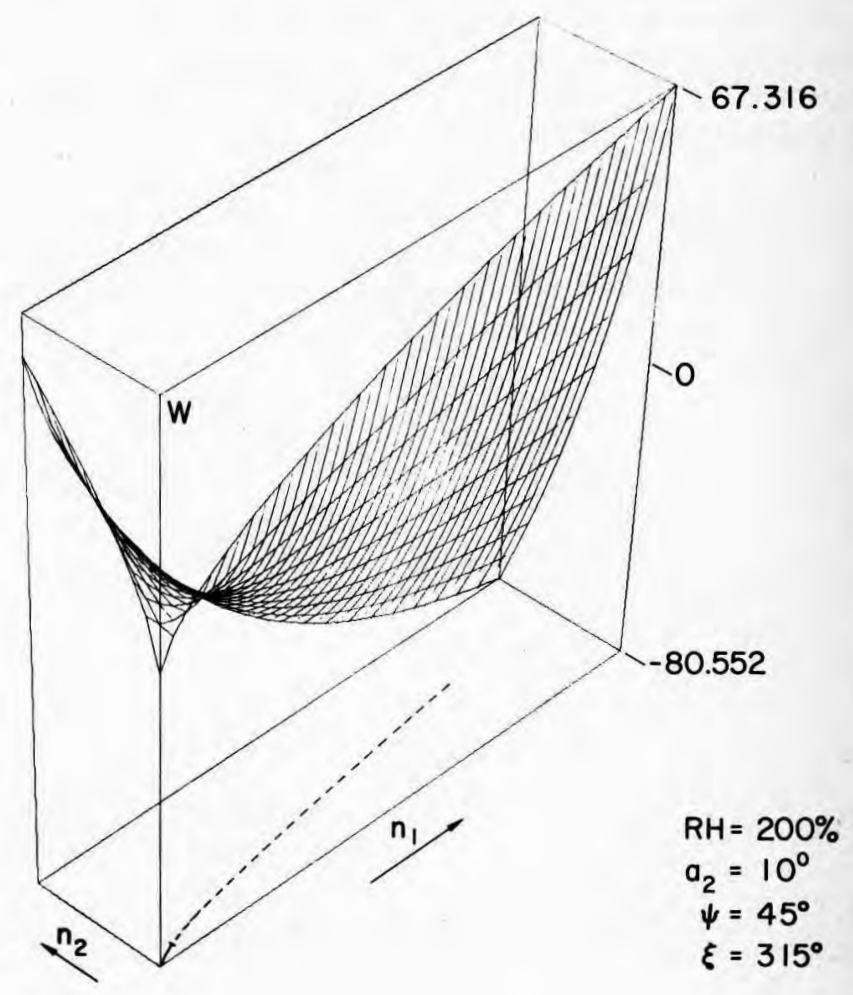

FIG. 3. The free energy surface for $\mathrm{H}_{2} \mathrm{O}-\mathrm{H}_{2} \mathrm{SO}_{4}$ droplet formation at $25^{\circ} \mathrm{C}$ with $R H=200 \%$ and $a_{2}=10^{\circ}$. All other conditions are the same as in Fig. 1. 


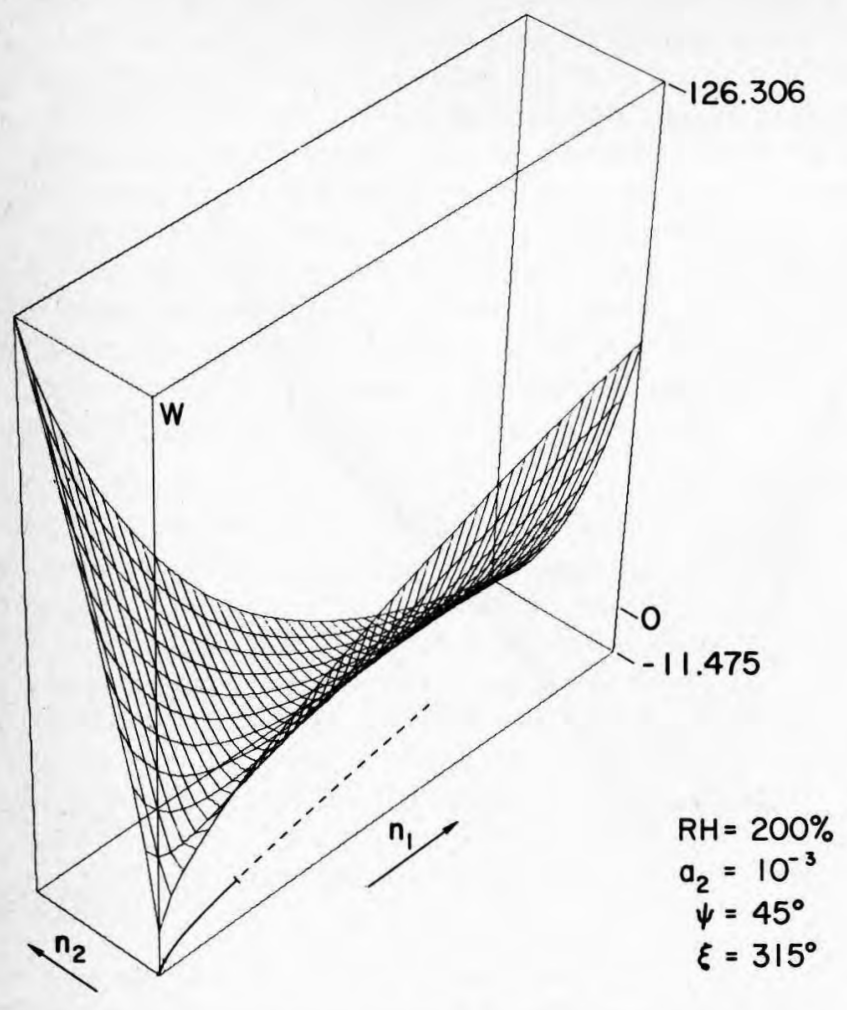

FIG. 4. The free energy surface for $\mathrm{H}_{2} \mathrm{O}-\mathrm{H}_{2} \mathrm{SO}_{4}$ droplet formation at $25^{\circ} \mathrm{C}$ with $R H=200 \%$ and $a_{2}=10^{-3}$. All other conditions are the same as in Fig. 1.

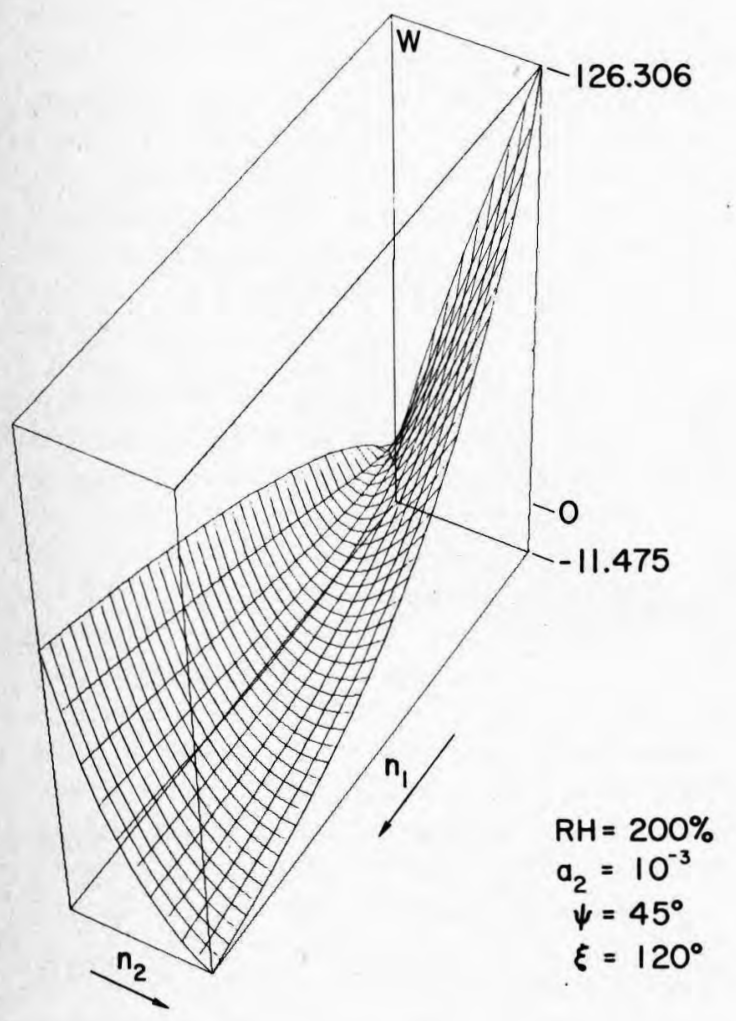

FIG. 5. This free energy surface is identical to the surface shown in Fig. 4, except that the viewing angle $\xi$ has been changed to $120^{\circ}$ about the $W$ axis.

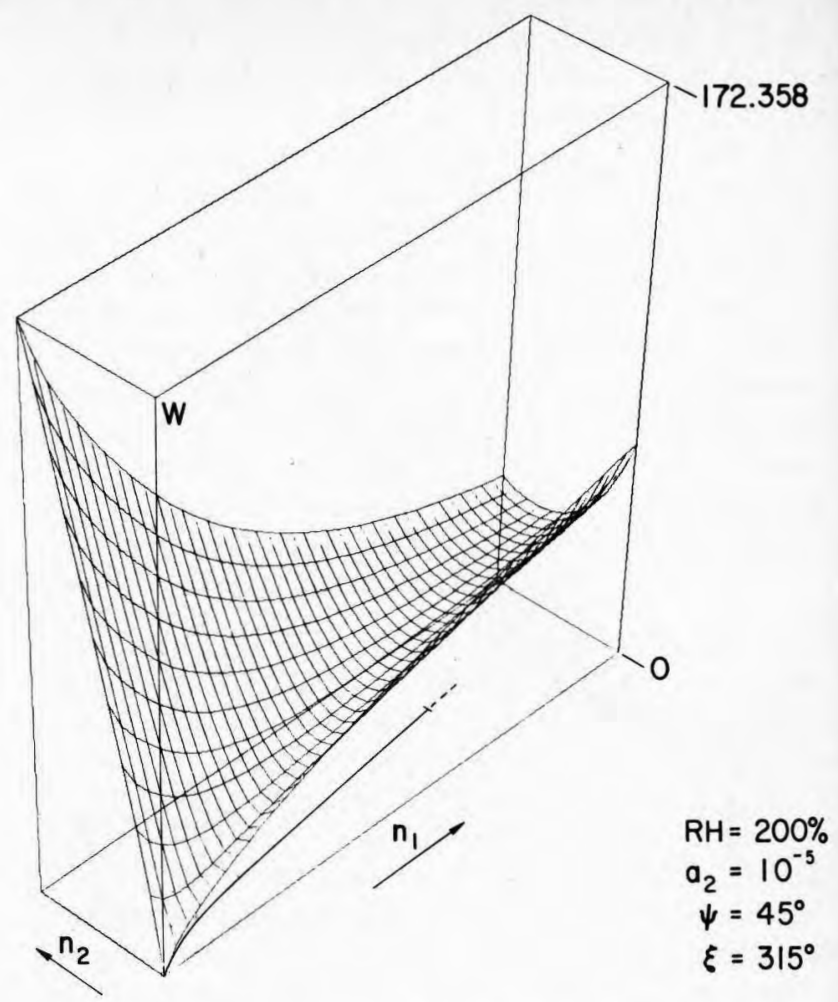

FIG. 6. The free energy surface for $\mathrm{H}_{2} \mathrm{O}-\mathrm{H}_{2} \mathrm{SO}_{4}$ droplet formation at $25^{\circ} \mathrm{C}$ with $\mathrm{RH}=200 \%$ and $a_{2}=10^{-5}$. All other conditions are the same as in Fig. 1.

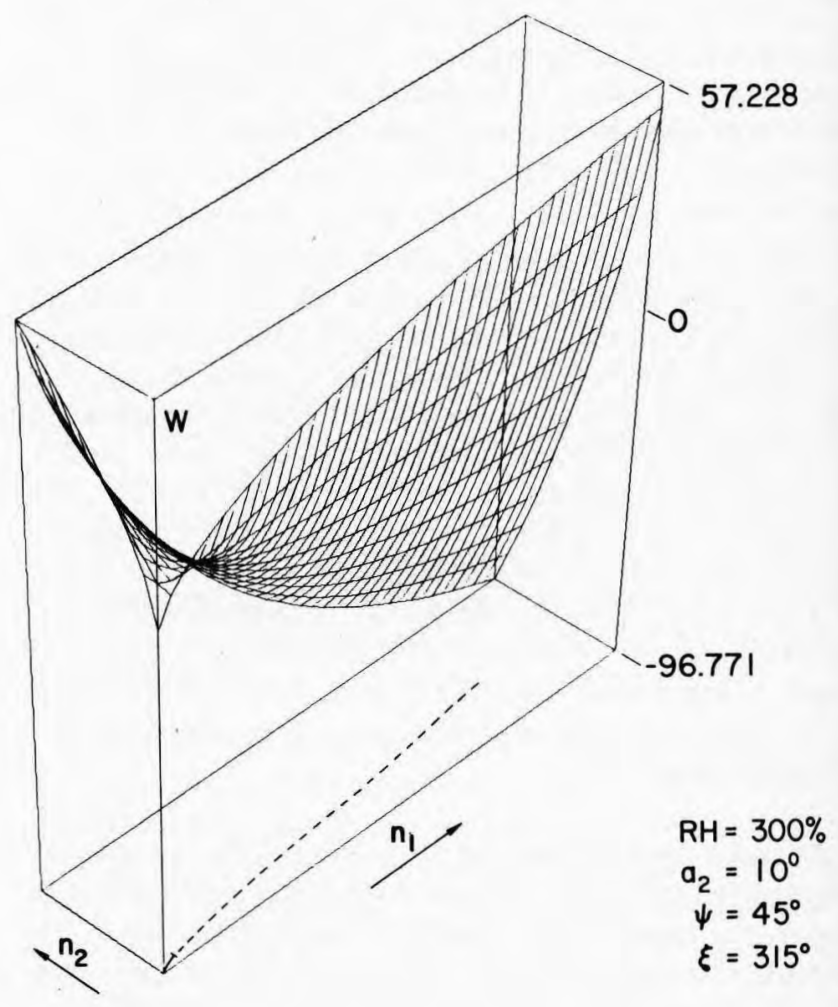

FIG. 7. The free energy surface for $\mathrm{H}_{2} \mathrm{O}-\mathrm{H}_{2} \mathrm{SO}_{4}$ droplet formation at $25^{\circ} \mathrm{C}$ with $\mathrm{RH}=300 \%$ and $\boldsymbol{a}_{2}=10^{\circ}$. All other conditions are the same as in Fig. 1. 


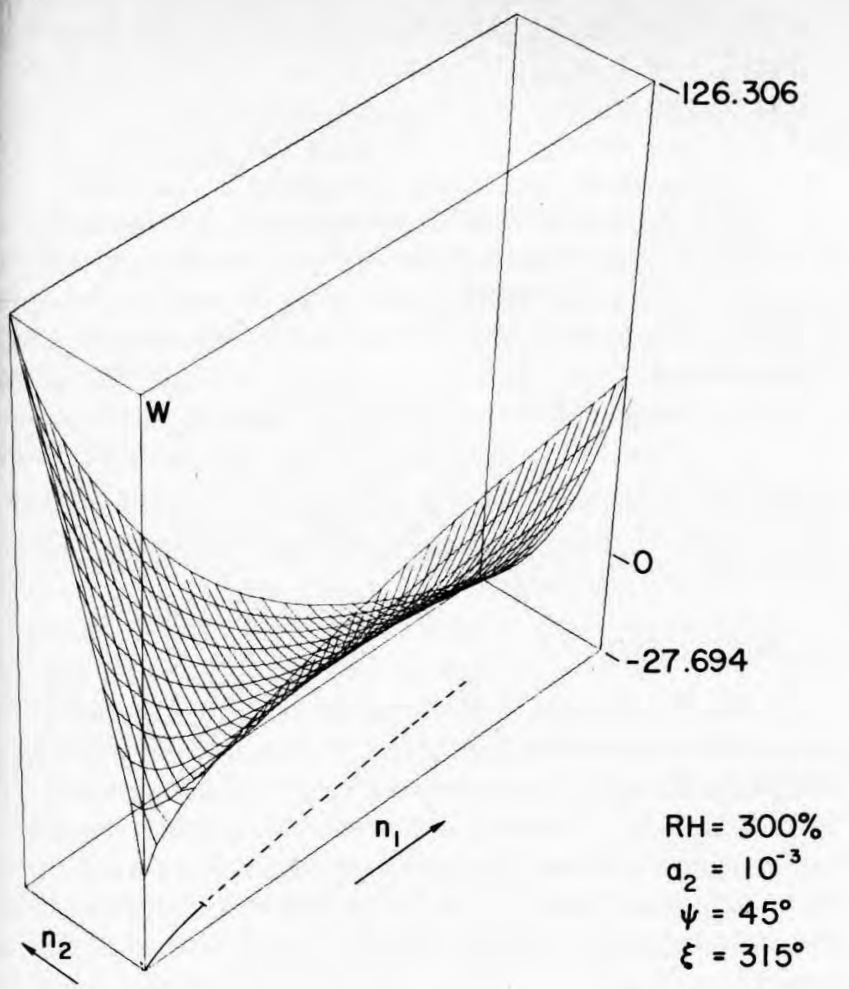

FIG. 8. The free energy surface for $\mathrm{H}_{2} \mathrm{O}-\mathrm{H}_{2} \mathrm{SO}_{4}$ droplet formation at $25^{\circ} \mathrm{C}$ with $\mathrm{RH}=300 \%$ and $\boldsymbol{a}_{2}=10^{-3}$. All other conditions are the same as in Fig. 1.

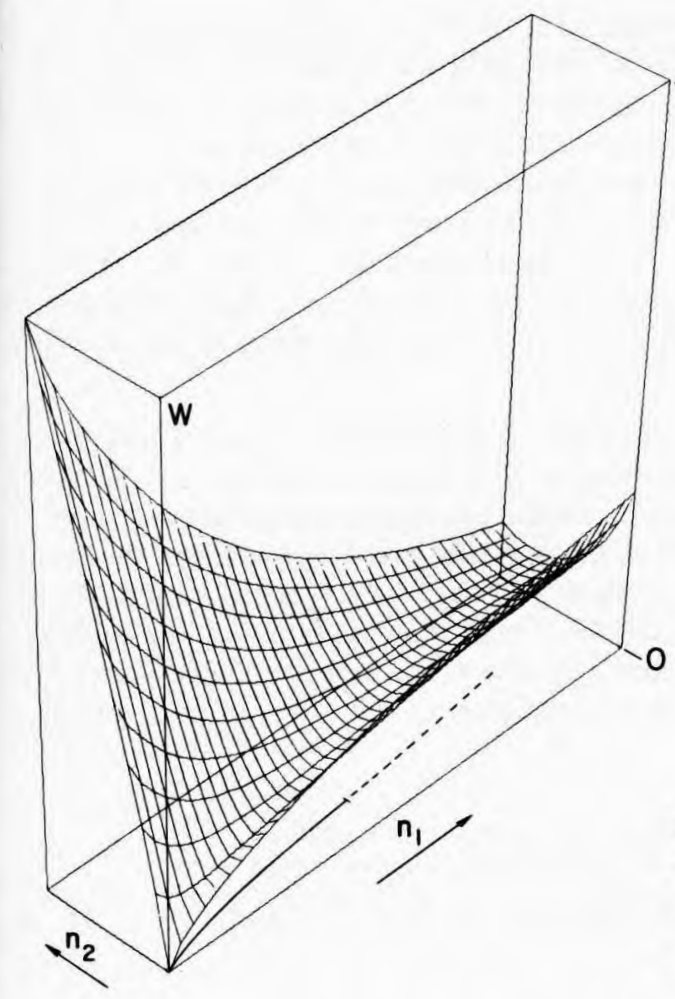

172.358

$\mathrm{RH}=300 \%$

$a_{2}=10^{-5}$

$\psi=45^{\circ}$

$\xi=315^{\circ}$

FIG. 9. The free energy surface for $\mathrm{H}_{2} \mathrm{O}-\mathrm{H}_{2} \mathrm{SO}_{4}$ droplet formation at $25^{\circ} \mathrm{C}$ with $\mathrm{RH}=300 \%$ and $a_{2}=10^{-5}$. All other conditions are the same as in Fig. 1.
TABLE I. The saddle point locations on the free energy surfaces. $n_{1}$ represents the $\mathrm{H}_{2} \mathrm{O}$ molecule concentration at the saddle, $n_{2}$ represents the $\mathrm{H}_{2} \mathrm{SO}_{4}$ molecule concentration, $W$ is the value of the free energy normalized to $k T$ at $25^{\circ} \mathrm{C}$ at the saddle, $P_{2}$ is the percent $\mathrm{H}_{2} \mathrm{SO}_{4}$ by weight in the drop at the saddle, and $R$ is the corresponding drop radius in angstroms.

\begin{tabular}{lrlrllll}
\hline $\begin{array}{l}\text { Figure } \\
\text { no. }\end{array}$ & $\begin{array}{l}\text { RH } \\
(\%)\end{array}$ & \multicolumn{1}{c}{$a_{2}$} & \multicolumn{1}{c}{$n_{1}$} & $n_{2}$ & \multicolumn{1}{c}{$W$} & \multicolumn{1}{c}{$P_{2}$} & $\begin{array}{l}\boldsymbol{R} \\
(\AA)\end{array}$ \\
\hline $\mathbf{1}$ & 50 & $10^{0}$ & 3.05 & 1.74 & 10.508 & 75.57 & 3.776 \\
2 & 50 & $10^{-3}$ & 30.09 & $\mathbf{9 . 9 7}$ & 41.010 & 64.33 & $\mathbf{7 . 3 1 2}$ \\
3 & 200 & $10^{0}$ & 1.91 & $\mathbf{0 . 8 7}$ & 7.153 & 71.26 & 3.082 \\
4 & 200 & $10^{-3}$ & 9.20 & 2.39 & 17.444 & 58.58 & 4.752 \\
5 & 200 & $10^{-3}$ & $\mathbf{9 . 2 0}$ & 2.39 & $\mathbf{1 7 . 4 4 4}$ & 58.58 & 4.752 \\
$\mathbf{6}$ & 200 & $10^{-5}$ & 28.05 & 4.80 & 33.384 & 48.23 & 6.554 \\
7 & 300 & $10^{0}$ & 1.67 & 0.72 & 6.430 & $\mathbf{7 0 . 0 4}$ & 2.912 \\
8 & 300 & $10^{-3}$ & 6.92 & 1.66 & 14.200 & 56.63 & 4.276 \\
9 & 300 & $10^{-5}$ & 18.13 & 2.72 & 24.239 & 44.96 & $\mathbf{5 . 5 9 4}$ \\
\hline \hline
\end{tabular}

from the perspective view, so we have calculated this point and the value of $W$ along the valley minima and plotted the projection of this path on the base of each paraellelepiped in Figs. 1-4 and 6-9. The saddle point is indicated graphically by the ending of the solid line on each projection, and the numerical values of $W, n_{1}, n_{2}, P_{2}$ (percent $\mathrm{H}_{2} \mathrm{SO}_{4}$ by weight), and drop radius, $R$, for each of the saddle points are listed in Table $I$. Saddle points were computed by solving the equations

$$
\left(\partial W / \partial n_{1}\right)_{n_{2}}=0, \quad\left(\partial W / \partial n_{2}\right)_{n_{1}}=0
$$

for $n_{1}$ and $n_{2}$ with $W$ given by Eq. (29).

Possibly the most interesting features displayed by these surfaces are the minima which exist along the grid line corresponding to $n_{2}=1$ and running parallel to the $n_{1}$ axis. These minima can be seen in Figs. 1-9, although somewhat unclearly in a few cases because of their depths and the scaling of the surface inside the parallelepiped. To exhibit these minima more dramatically, we have taken a two dimensional cut from Fig. 4 , and, in Fig. 10, have plotted $W$ along this cut as a function of the number of $\mathrm{H}_{2} \mathrm{O}$ molecules, $n_{1}$, for a single $\mathrm{H}_{2} \mathrm{SO}_{4}$ molecule, i.e., $n_{2}=1$. The minimum clearly shows hydrate formation in the vapor phase. The profile in Fig. 10 indicates that the hydrate is a far more stable species in the vapor state than anhydrous $\mathrm{H}_{2} \mathrm{SO}_{4}$.

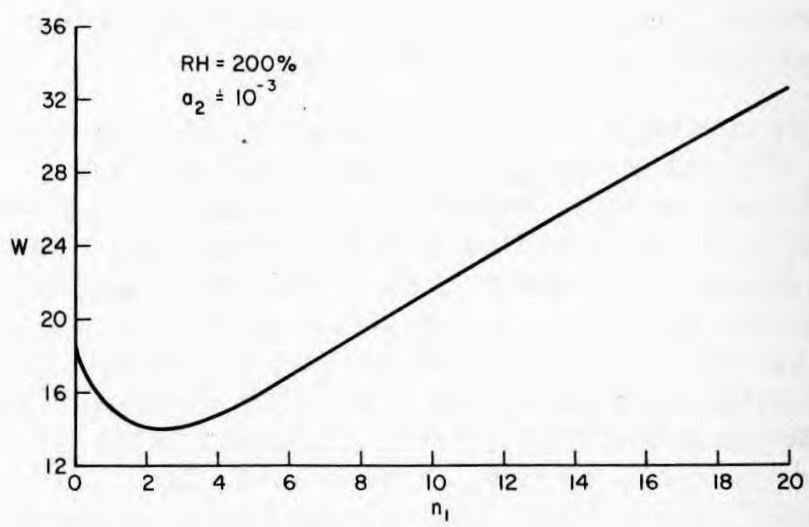

FIG. 10. A two dimensional profile from the surface in Fig. 4 with $R H=200 \%$ and $a_{2}=10^{-3}$. The profile shows the free energy $W$ of hydrate formation for one $\mathrm{H}_{2} \mathrm{SO}_{4}$ molecule and up to 20 $\mathrm{H}_{2} \mathrm{O}$ molecules. 


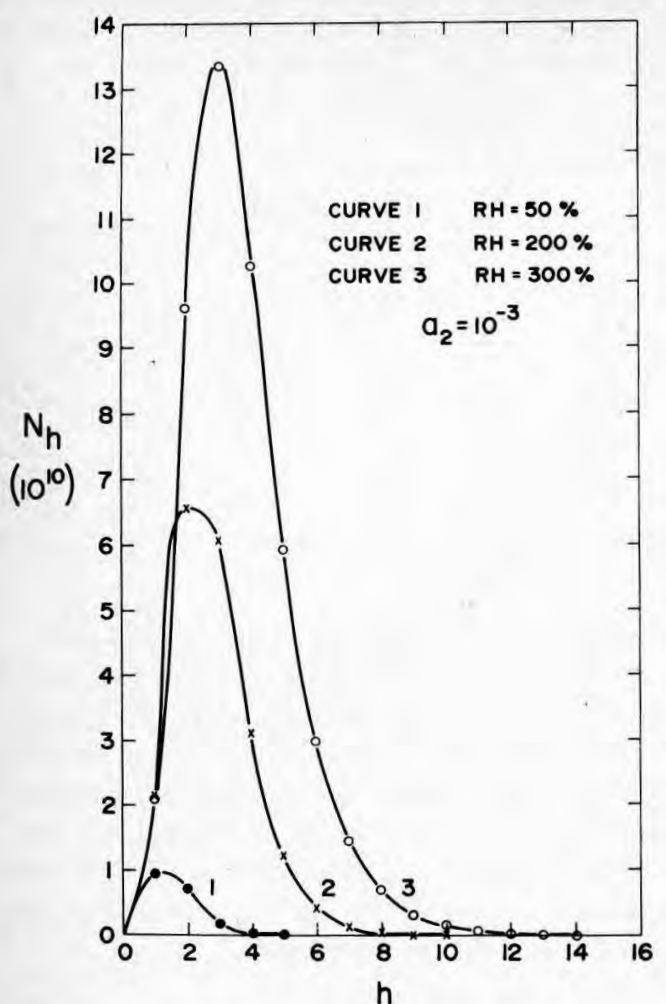

FIG. 11. The number of $\mathrm{H}_{2} \mathrm{SO}_{4}$ hydrates, $N_{h}$, with $h$ molecules of $\mathrm{H}_{2} \mathrm{O}$ per hydrate for $a_{2}=10^{-3}$ and $\mathrm{RH}=50 \%$ (Curve 1), $R \mathrm{HH}$ $=200 \%$ (curve 2), and $R H=300 \%$ (curve 3 ). The solid lines connecting the values of $N_{h}$ at each value of $h$ are to aid in viewing the distribution only.

Using the formalism developed in Sec. II, we can characterize these hydrates in more detail. Equation (1) is an expression for $W_{h}^{\prime}$, the reversible work or free energy required to form a drop containing one $\mathrm{H}_{2} \mathrm{SO}_{4}$ molecule and $h \mathrm{H}_{2} \mathrm{O}$ molecules from an initially homogeneous phase. That this is not the same as the value of $W$ plotted in Fig. 10 is explained in the discussion following Eq. (1). It is, however, related to $W$ by Eqs. (15)-(17). The difference between $W_{h}^{\prime}$ and $W$ lies, essentially, in the standard states chosen for the free energies. The reversible work, $W$, in Fig. 10 is calculated with reference to pure $\mathrm{H}_{2} \mathrm{SO}_{4}$ and pure $\mathrm{H}_{2} \mathrm{O}$ as the independent species. On the other hand, $W_{h}^{\prime}$ in Eq. (1) refers to a pure hydrate and pure $\mathrm{H}_{2} \mathrm{O}$ standard.

By relating $W_{h}^{\prime}$ to $W$ we can, by using either Eq. (18) or (23), calculated $N_{h}$, the number of hydrates with $h$ molecules of $\mathrm{H}_{2} \mathrm{O}$. These two expressions for $N_{h}$ differ only in the approximation used in arriving at Eq. (23). $N_{h}$ has been computed for $R H^{\prime}$ s of $50 \%, 200 \%$, and $300 \%$, and an $a_{2}$ of $10^{-3}$; the results appear in Fig. 11. The values of $\theta$, the total number of hydrates, and $Q$, a type of partition function defined in Eq. (20), employed in this calculation are listed in Table II. Curve 1 in Fig. 11 corresponds to $R H=50 \%$, Curve 2 to $R H=200 \%$, and Curve 3 to $R H=300 \%$. Curves 2 and 3 were calculated from Eq. (23) since, for these conditions, the approximation, $N_{a} / N \ll Q$, is valid. The approximation fails, however, for $R H<100 \%$, since $Q$ is found to be too small. Therefore, curve 1 was computed using Eq. (18).
The plots in Fig. 11 show that virtually all the hydrates contain from 1 to $14 \mathrm{H}_{2} \mathrm{O}$ molecules. In fact, for curves 2 and 3 , hydrates with 1 to 8 and 1 to $14 \mathrm{H}_{2} \mathrm{O}$ molecules per hydrate, respectively, account for more than $99.9 \%$ of all hydrates in each case. In addition, the total number of hydrates $\theta$ for the conditions corresponding to curves 2 and 3 account for more than $94 \%$ and $95 \%$, respectively, of all $\mathrm{H}_{2} \mathrm{SO}_{4}$ molecules present. For curve 1 with an $R H$ of only $50 \%$, however, $99.8 \%$ of all hydrates contain from 1 to 4 molecules of $\mathrm{H}_{2} \mathrm{O}$ per hydrate, while $\theta$ accounts for only about $61 \%$ of the total $\mathrm{H}_{2} \mathrm{SO}_{4}$ concentration. Clearly the number of $\mathrm{H}_{2} \mathrm{SO}_{4}$ molecules in the hydrated form depends very strongly on the concentration of $\mathrm{H}_{2} \mathrm{O}$; but even for $\mathrm{RH}<100 \%$, most $\mathrm{H}_{2} \mathrm{SO}_{4}$ molecules are bound as hydrates.

\section{DISCUSSION}

To our knowledge, this is the first time that rather large sections of the free energy surface for $\mathrm{H}_{2} \mathrm{O}-\mathrm{H}_{2} \mathrm{SO}_{4}$ droplet formation have been calculated and represented in this fashion. These surfaces have revealed several interesting features, a number of which have already been discussed in Sec. IV. There are, however, a few more that deserve mention here. First, there is the effect that the uncertainty in the surface tension (see Sec. IV) has on the surfaces. Morgan and Davis's $s^{15}$ (MD) values for the surface tension were used in Eq. (29); for $R H=200$ and $a_{2}=10^{-3}$, the resulting surface, when compared with that in Fig. 4, revealed that the net effect was a lowering of the entire surface. The hydrate minimum was lowered by $5.4 \%$ and the saddle point by roughly $5.2 \%$.

A $5.2 \%$ reduction in the free energy at the saddle would have an enormous effect on the binary nucleation rate per se, but the net effect on hydrate formation is much less because the entire surface is lowered, not just the minimum and saddle point. We have recalculated Curve 2 in Fig. 11 based on this surface and have found the general shape to be the same with the maximum value of $N_{n}$ increased by approximately $52 \%$. The percent of $\mathrm{H}_{2} \mathrm{SO}_{4}$ bound up as hydrates changes only negligibly, i.e., $<1.6 \%$.

Another interesting feature of the surfaces with respect to hydrate size distribution (see Fig. 11) is the correlation between the hydrate sizes predicted here for the vapor phase and that actually found for the solid phase by Giauque and co-workers. ${ }^{9}$ As mentioned in Sec. I, the number of $\mathrm{H}_{2} \mathrm{O}$ molecules found per hydrate in the solid phase ranged from 1 to 8 . These sizes agree nicely with those predicted in Fig. 11. In fact, as the

TABLE II. Values for $\theta$, the total number of hydrates, and $Q$, the partition function, used to calculated curves 1,2 , and 3 in Fig. 11 .

\begin{tabular}{lll}
\hline $\begin{array}{l}\text { Curve } \\
\text { number }\end{array}$ & $\theta$ & $Q$ \\
\hline 1 & $1.8378 \times 10^{10}$ & $1.2535177 \times 10^{-7}$ \\
2 & $1.9690 \times 10^{11}$ & $2.3397135 \times 10^{-6}$ \\
3 & $4.6889 \times 10^{11}$ & $8.5615802 \times 10^{-6}$ \\
\hline
\end{tabular}


$\mathrm{H}_{2} \mathrm{O}$ concentration increases towards that of the condensed phase, i.e., as supersaturation increases, the number of $\mathrm{H}_{2} \mathrm{O}$ molecules per hydrate agrees well with Giauque's values. ${ }^{9}$

This internal consistency evidenced by the droplet model suggests that it will be a reasonable approximation in a theory of nucleation, especially at $50 \% \mathrm{RH}$ where the nuclear size is large. It is known ${ }^{17}$ to yield good results for the theory of nucleation of $\mathrm{H}_{2} \mathrm{O}$ alone, and we may now hope that it will be equally useful for $\mathrm{H}_{2} \mathrm{O}-\mathrm{H}_{2} \mathrm{SO}_{4}$ mixtures.

An important final feature suggested by these surfaces and by the hydrate formation is, as indicated above, the need to alter the mechanism for the binary nucleation process in the $\mathrm{H}_{2} \mathrm{O}-\mathrm{H}_{2} \mathrm{SO}_{4}$ system. Until now, droplet growth over the surfaces, illustrated in Figs. 1-9, has been thought to occur by acquisition of single $\mathrm{H}_{2} \mathrm{O}$ and $\mathrm{H}_{2} \mathrm{SO}_{4}$ molecules, one at a time. It will be shown in a following paper that the growth actually involves hydrate collisions, and that between each addition of an acidbearing molecule (hydrate) the cluster comes to local equilibrium with respect to $\mathrm{H}_{2} \mathrm{O}$; i. e., between addition of $\mathrm{H}_{2} \mathrm{SO}_{4}$ molecules, the $\mathrm{H}_{2} \mathrm{SO}_{4}$ in the cluster behaves as an involatile solute.

\section{ACKNOWLEDGMENTS}

This research was supported by the National Science Foundation under Grant No. GP-28722X.

The authors thank John B. Fenn, Jr. for many useful discussions in connection with the theory of hydration. It was in fact during one of these discussions that the necessity for hydration of the $\mathrm{H}_{2} \mathrm{SO}_{4}$ molecule was rec- ognized. The authors also thank Donald Peters of the Institute of Geophysics and Planetary Physics at the University of California, Los Angeles, for providing the three dimensional perspective plotting routine used to generate the surfaces shown in this paper.

${ }^{1}$ T. C. Hall, Jr., "Photochemical Studies of Nitrogen Dioxide and Sulfur Dioxide," $\mathrm{Ph} . \mathrm{D}$. thesis, University of California, Los Angeles, 1953.

${ }^{2}$ P. A. Leighton, Photochemistry of Air Pollution (Academic, New York, 1961), pp. 235-53.

${ }^{3}$ E. R. Stephens and M. A. Price, Aerosols and Atmospheric Chemistry, edited by G. Hidy (Academic, New York, 1972), p. 167.

${ }^{4}$ R. D. Cadle, Ref. 3, p. 141.

${ }^{5} \mathrm{~J}$. Bricard, M. Cabane, G. Madelaine, and D. Vigla, Ref. 3, p. 27.

${ }^{6}$ G. J. Doyle, J. Chem. Phys. 35, 795 (1961).

${ }^{7}$ P. Mirabel and J. L. Katz, J. Chem. Phys. 60, 1138 (1974).

${ }^{8}$ H. Reiss, J. Chem. Phys. 18, 840 (1950).

${ }^{9}$ W. F. Giauque, E. W. Hornung, J. E. Kunzler, and T. R. Rubin, J. Am. Chem. Soc. 82, 62 (1960).

${ }^{10}$ L. Sabinia and L. Terpugow, Z. Phys. Chem. A 173, 237 (1935).

${ }^{11}$ W. J. Dunning, Nucleation, edited by A. Zettelmoyer (Decker, New York, 1969), Chap. 1.

${ }^{12}$ W. F. Giauque, J. E. Kunzler, and E. W. Hornung, J. Am. Chem. Soc. 78, 5482 (1956).

${ }^{13}$ Chemical Engineers Handbook, 4th ed., (McGraw-Hill, New York, 1963), Table 3-120.

${ }^{14} \mathrm{G}$. N. Lewis and M. Randall, Thermodynamics, 2nd ed. (McGraw-Hill, New York, 1961), pp. 207-208.

${ }^{15}$ J. L. R. Morgan and C. E. Davis, J. Am. Chem. Soc. 38, 555 (1916).

${ }^{16} \mathrm{~J}$. I. Gmitro and T. Vermeulen, AICHE J. (Am. Inst. Chem. Eng.) 10, 740 (1964).

${ }^{17}$ R. H. Heist and H. Reiss, J. Chem. Phys. 59, 665 (1972). 